\title{
Causes and Effect of Occupational Stress and Coping on Performance with Special Reference to Length of Service: An Empirical Study Using Multinomial Logistic Regression Approach
}

\author{
Kanaka Durga Veer Prasad ${ }^{1 *}$, Rajesh Vaidya² \\ ${ }^{1}$ Rashtrasant Tukadoji Maharaj Nagpur University, Nagpur, India \\ ${ }^{2}$ Department of Management and Technology, Shri Ramdeobaba College of Engineering and Management, \\ Nagpur, India \\ Email: ^k.d.prasad@cgiar.org, rwvaidya@gmail.com
}

How to cite this paper: Prasad, K. D. V., \& Vaidya, R. (2018). Causes and Effect of Occupational Stress and Coping on Performance with Special Reference to Length of Service: An Empirical Study Using Multinomial Logistic Regression Approach. Psychology, 9, 2457-2470.

https://doi.org/10.4236/psych.2018.910141

Received: August 31, 2018

Accepted: September 17, 2018

Published: September 20, 2018

Copyright (c) 2018 by authors and Scientific Research Publishing Inc.

This work is licensed under the Creative Commons Attribution International License (CC BY 4.0).

http://creativecommons.org/licenses/by/4.0/

(c) (i) Open Access

\begin{abstract}
The manuscript presents the outcome of our research study on effect of occupational stress, coping strategies adopted, length of service and their relation with performance of employees. A survey using an undisguised questionnaire was carried on the employees working in the International Agricultural Research Institute and Information Technology sector in Indian Metro, Hyderabad. The data from the 756 respondents, including 381 women and 375 men responses was used for analysis. The occupational stress was measured using 14 stress causing components-workload, co-workers, peer, peer-support, role ambiguity, role conflict, career, harassment, psychological factors, physiological factors, behavioural factors, social support, job control, approach coping and voidance coping, length of service on dependent factor Performance of the respondents from the International Agricultural Research Institute and IT sector. The effect on dependent variable performance with the independent factors length of service was divided into 4 groups in $1-5$ years, 6 - 10 years, 11 - 15 years and $>15$ years of service, occupational stress factors, coping strategies were measured. The overall C-Alpha value is 0.92 for overall components, 0.91 for occupational stress components, 0.92 for overall coping, 0.69 for performance; whereas 0.69 for avoidance coping 0.69 for approach coping. The likely hood odds rations (ORs) were estimated to predict degree of association of occupational stress, coping strategies, length of service with performance of the employees, gender and age differences.
\end{abstract}

\section{Keywords}

Occupational Stress, IT Sector, IARI, Length of Service, Coping, Gender 


\section{Introduction}

\section{Definition of Occupational Stress}

In general, the stress is the body's nonspecific response to a demand placed on it (Selye, 1974). The stress is a condition or feeling experienced when a person perceives that demands exceed the personal and social resources, an individual is able to mobilize (Lazarus, 1966). According to Schuler (1980), stress is a dynamic condition in which an individual is confronted with an opportunity, demand, or resource related to what the individual desired and for which the outcome is perceived to be both uncertain and improvement. Occupational stress or job stress is experienced when an employee is poor-fit or misfit with characteristics of his/her work and its environment causing psychological and health strains. Occupational stress can be experienced when the requirements of the assigned job or task are more than the abilities of an employee, and the constraints on available resources to perform the task while interacting with the working conditions (Rose \& Vega, 1984). Occupational stress is a situation wherein job related components that communicate with an employee to change his/her conscious mind conditions resulting in an employee moving away from normal functioning (Beehr \& Newman, 1978). Work stress is an unpleasant physical and emotional stress response that occurs when there is misfit between demands of the work and capacity and resource requirements of an employee (Sumaneet, 2005).

The occupational stress is predominant in working sector and in particular IT sector and Banking. However recently several studies reported that agricultural research sector of Hyderabad Metro is no exception from the side effects of occupational stress related problems. The low productivity, absenteeism, fatigue, low motivation on instinct to work, dislike in doing and learning new things and in turn effect on employee performance and loss of interest in work are occupational stress (Cooper, 1978; Matteson \& Ivancevich, 1987).

Selye (1956), an Austrian Endocrinologist introduced the concept of stress into life sciences. The stress is defined as external force or pressure in mechanical sciences (Pestonjee, 1999). The emotional stressors induce the well-being through emotional, cognitive, behavioural and conscious factors (Levi, 1998). The role ambiguity, role overload, role conflict and unfriendly working atmosphere are general causes of the stress (Chand \& Sethi, 1997). The nature of work given to an employee is also one of the stress components. The employees who are allocated the work interested to him/her will mitigate stress well in comparison with who are assigned uninterested work (Tread Gold, 1999).

\section{Review of Literature}

Sateesh Kumar \& Madhu (2012) examined the influence of components liable for work stress among the employees in the manufacturing industries in Kerala, India. A sample of 75 Engineers, 110 Supervisors and 675 Workers is selected from manufacturing industries in Kerala, India. A seven stress causing compo- 
nents used, in consultation with safety experts for the evaluation of work stress. The instrument developed by using these components had validity, unidimensionality and reliability. The results indicated the studied stress components are responsible for work stress among all the categories of employees in these industries. The multinomial logistic regression model used found good fit in predicting the work stress in manufacturing industries.

Prasad et al. (2016) observed occupational stress factors significantly influencing the performance of CBSE affiliated school teachers causing some physiological disorders and affecting the performance. The further reported in their multinomial logistic regressions study that demographic variables like gender, age, marital status, children and general health factors like diabetes, hypertension significantly influence the performance.

Prasad et al. (2018) in another study reported statistically significant association among occupational stress and stress factors like hours/week, job insecurity and social support and their effect on performance.

Suryawanshi et al. (2015), Sateesh Kumar \& Madhu (2012), Stephen (2014), Lotfizadeh et al. (2014) studied occupation stress and its factors using multinomial logistic regression. Irawanto et al. (2015) applied hierarchical regression analysis to conclude that stressors and occupational stress significantly decrease the performance of women. This study further reported that demographic variables will have moderating association of stressors and occupational stress with the performance. Awadh et al. (2015) in their case study on effects of workplace stress on employee performance in Kenyan government employees reported a positive correlation between time pressure, long working hours and job demand with performance. The study observed that time pressure was major factor contributing to occupational stress and effecting the employee performance.

Therefore, the researchers used multinomial logistic regression to study the components of occupational stress, coping with relation to performance and with a special reference length of service of the employees from IARI and IT sector.

\section{Need for This New Innovation}

The researchers reported several studies on occupational stress and its effect on performance. However, most of the research studies are limited to information and bank technology, hospital nurses, using the constructs of the occupational stress. Even though after a thorough review not able to find a single review on employees working in the area of agricultural research sector. Further, the Hyderabad metro hosts several national and international agricultural research institutes. Medium and large seed industries, life sciences and biotech companies and $>500$ IT sector companies were hosted by Hyderabad Metro. The researchers pursued this study keeping in mind that stress is common to all working community, notwithstanding type of job or sector where employees. Most of the 
studies carried out even ordinal variables as continuous not knowing whether it right or wrong. In the study research study, the effect on performance caused by occupational stress factors, coping and length of service experienced by the respondents in IARI and IT sector were categorized into three levels, low effect, moderate effect and high effect. Therefore, the outcome variable is categorical and has more than two categories. We have used the Statistical Package for Social Sciences (SPSS ver 25.0) and the dependent variables stored as nominal variables. The multinomial logistic regression is used to predict the nominal dependent variable in the study i.e. the effect on performance with occupational stress, approach coping, avoidance coping and the length of service. The multinomial logistic regression allows interactions between independent variable to predict the dependent variable.

\section{Objectives and Hypotheses}

\subsection{Research Question}

Is the occupational stress, coping is related and length of service related to performance of International Agricultural Research Institute (IARI and IT sector employees)?

\subsection{Objective and Hypotheses}

To study if there is any relation of occupational stress, coping and length of service on performance in IARI and IT sector employees.

Based on the identified problem, research question and the objectives the following hypotheses were formed:

$\mathrm{H}_{01}$ : Occupational stress, coping are not related to the Performance of IARI and IT sector employees.

$\mathrm{H}_{11}$ : Occupational stress and coping are related to the Performance of IARI and IT sector employees.

$\mathrm{H}_{02}$ : Length of service is not related to IARI and IT sector employees.

$\mathrm{H}_{12}$ : Length of service is related to IARI and IT sector employees.

\section{Research Methodology}

Conceptual Framework: The proposed framework was adopted based on outcomes of the research studies by Selye (1980), and Prasad et al. (2015, 2016, 2018). The 14 independent stress causing factors, workload, co-workers, peer support, role ambiguity, role conflict, career, harassment, psychological factors, physiological factors, behavioural factors, social support and Job control, coping strategies approach and avoidance coping strategies on depending factors Performance of IARI and IT sector employees. The conceptual framework for occupational stress, coping and performance is provided in Figure 1.

\subsection{Determination of Sample Size}

Cochran (1977) formula was used to calculate a representative sample for proportion as 


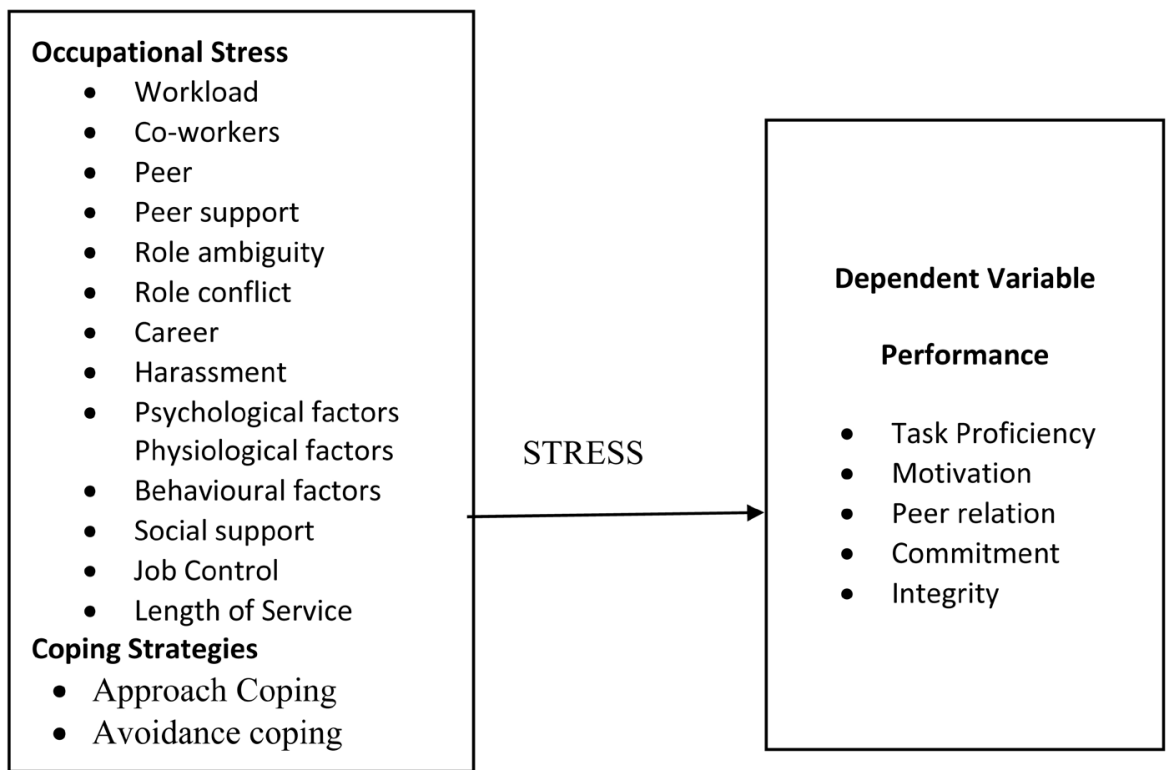

Figure 1. Conceptual frame work: occupational stress vs performance.

$$
n_{0}=\frac{z^{2} p q}{e^{2}}
$$

where $n_{\mathrm{o}}$ is the sample size, $z$ is the selected critical value of desired confidence level, $p$ is the estimated proportion of an attribute that is present in the population, $q 1 p$ and $e$ is the desired level of precision was used to determine the sample size as the total population size is not known for IARI and IT sector where population is infinite, assuming the maximum variability which is equal to $50 \%$ $(p=0.5)$ and taking $95 \%$ confidence level with $\pm 5 \%$ precision, the required sample size is

$$
\begin{gathered}
p=0.5 \text { and hence } q=1-0.5=0.5 ; e=0.05 \text { and } z=1.96 \\
n_{0}=\frac{(1.96)^{2}(0.5)(0.5)}{(0.05)^{2}}=384.16=384
\end{gathered}
$$

A sample size of 756 was selected using simple random sample sampling where each member of the subset has an equal probability of being chosen and data from 850 respondents was used for the analysis. The demography of sample presented in Table 1.

Research Instrument for data gathering. A structured unbiased questionnaire consisting of three scales-1) a modified version of Occupational stress scale based occupational stress index (OSI) developed by Srivastava \& Singh (1984) which has 59 statements including 20 reversed keyed questions covering 14 factors using five-point Likert scale ranging from Strongly agree (5) to Strongly disagree (1);2) Performance scale is based on Higher-Order performance Dimensions model (Campbell et al., 1990) consisting 20 statements covering 5 factors using a 5 point Likert scale with values ranging from 1 (strongly disagree) to 5 (strongly agree). The statements consist 15 true keyed and 5 reverse keyed; 
Table 1. Demography of sample: frequencies of gender and age groups in the sample.

\begin{tabular}{|c|c|c|}
\hline Gender & Frequency & Percent \\
\hline Women & 381 & 50.40 \\
\hline Men & 375 & 49.60 \\
\hline \multirow[t]{2}{*}{ Total } & 756 & 100 \\
\hline & Age group & \\
\hline $20-29$ & 226 & 29.9 \\
\hline $30-34$ & 265 & 35.0 \\
\hline $35-39$ & 173 & 22.9 \\
\hline$>40$ & 92 & 12.2 \\
\hline \multicolumn{2}{|c|}{ Source: Primary Data. } & 100 \\
\hline
\end{tabular}

3) The coping strategies scale based on by Srivastava (2001) has 34 statements describing the factors Approach and Avoidance copings using a Likert-type scale with 5 (Almost Always) and 1 (Never) are main source for the primary data collection. The questionnaire was divided into 2 sections-in the Section I, Demographic variables like age, sex, number of years of experience, qualifications and other background information/personal details of the respondent were collected. The Section II of questionnaire was used to find out the stress levels of the employees, coping strategies, and impact of the stress, length of service on performance and IARI and IT sector employees. To measure each factor, a range of 4 6 statements were given but all these questions were mixed systematically.

\subsection{Brief Description of the Questionnaire}

The questionnaire was prepared to collect the data of the research variables were both demographic and psychographic in nature. Personal statistics that include information on gender, age group, education details, and marital status are the demographic variables used in this study. The associated occupational stress and psychographic variables studied are: occupational stress, coping (studied as avoidance coping and approach coping) and performance. The data was collected in the form the questions (Experience in years) and the groups are $1-5$, years, 6 - 10 years $11-15$ years, and $>15$ years. The dichotomous variables (YES/NO) using the statements like "Have you experienced occupational stress" (YES/NO); "Did stress effect your performance?" YES/NO and so on.

Data Analysis. The descriptive statistical analysis, reliability statistics, multinomial logistic regression analysis was carried out to analyze the data for drawing inferences from our research data. To assess the data normality Shapiro-Wilk test was carried out and for this approximately normally distributed data $p=0.3262$ indicating normally distribution of data.

Reliability methods: Cronbach's alpha statistic was used to measure the internal consistency, reliability of our research instrument, and the second reliabil- 
ity statistic split-half co-efficient Spearman-Brown formula (Cronbach, 1951; William Trochim, 2006) and subsequently elaborated by others (Novick \& Lewis, 1967; Kaiser \& Michael, 1975). The estimated values of the Cronbach's alpha are indicated in Table 2. The Statistical Package for Social Sciences (SPSS ver. 25) was used to analyze descriptive statistic and dispersions. To predict the dependent factor based on independent factors the multinomial logistic regression analysis carried out (IBM Corp., 2017).

Reliability test of the Questionnaire: The outcome of the survey was measured using a Likert-type scale with items 1 - 5 for all the questionnaires. In case of performance a 9 point Likert type scale was used (+4 to -4$)$ was converted to a 5 point scale for ease of calculation and analysis. The reliability statistic Cronbach's alpha coefficient value (C-alpha) was calculated to measures the internal consistency of the instrument in totality (Gay, Mills, \& Airasian, 2009). A brief pilot study was used to test the instrument using the data of 100 employees and using SPSS ver 25.

The reliability statistics values are: The overall C-alpha for the study is 0.92; for occupational stress over all is 0.91 ; coping over all is 0.92 and approach coping is 0.69 and avoidance coping is 0.69 . The second reliability statistics were split-half (odd even) correlation is 0.81 ; spearman brown prophecy is 0.89 indicating a strong internal consistency and reliability of the survey instrument. The reliability statistics are presented in Table 2.

The Mean, Standard Deviation in mean responders on factor scale for all the 14 stress causing independent factors and dependent factor Performance and estimated and presented in Table 4 . The overall mean and standard deviation was estimated from the responses. The overall mean was 3.08 and standard deviation was 0.37. Based on this Occupational stress score for Low, Medium and High stress determined (Table 3 \& Table 4 ).

For a symmetric distribution, the expected range will be 6 times of standard deviation $(\sigma)$ and better approximation makes it a normal distribution. For this study range is in near normal distribution and is nearly equal to the 6 times of standard deviation (Francis, 2008; Annamalai \& Nandagopal, 2014). The occupational study questionnaire consists has 59 questions, with 14 questions are reverse keyed and values ranging 1 and 5, therefore, the minimum range 59

Table 2. Cronbach's alpha values for factors used in this study.

\begin{tabular}{ccc}
\hline Sl. No & Factor & Cronbach's alpha \\
\hline 1 & Overall C-alpha & 0.92 \\
2 & Occupational Stress overall & 0.91 \\
3 & Coping overall & 0.92 \\
4 & Approach coping & 0.69 \\
5 & Avoidance coping & 0.69 \\
\hline
\end{tabular}

Overall: Split-Half (odd-even) Correlation: 0.81 Spearman Brown Prophecy: 0.89. Source: Primary Data. 
Table 3. Mean and standard deviation of occupational stress factors, psychological well-being and performance.

\begin{tabular}{|c|c|c|}
\hline Factor & Mean $\bar{X}$ (Overall) & Standard Deviation \\
\hline Occupational stress & 3.08 & $\sigma=0.37$ \\
\hline Approach coping & 3.17 & 0.30 \\
\hline Avoidance coping & 2.80 & 0.32 \\
\hline Performance & 3.30 & 0.31 \\
\hline
\end{tabular}

Table 4.Rating of the score for occupational stress.

\begin{tabular}{cc}
\hline Total rating range of the score & Level of influence \\
\hline$(\bar{X}+\sigma)=3.12+0.37=3.45(>3.45)$ & High Level \\
$(\bar{X}-\sigma)=3.12-0.37=2.75(<2.75)$ & Low level \\
2.77 to 3.45 & Moderate Level \\
\hline
\end{tabular}

$(1 \times 59)$ and the maximum range value is $295(5 \times 59)$ the range is the difference between minimum and maximum values-236 for 59 questions. The overall range 236 is near to the 6 time standard deviation (0.39).

From the above Mean, the standard deviation is added and the maximum ceiling for the higher stress is set. The difference between mean and standard deviations calculated to find out the minimum ceiling for low level of occupational stress. The level between minimum and maximum is set as medium occupational stress level (Prasad et al., 2016, 2018).

\section{Results}

To assess the occupational stress, approach coping, avoidance coping, and length of service effect on the dependent factors Performance, multinomial regression analysis was carried out. The model also will predict the probabilities of the influence of occupational stress, approach and avoidance coping, and length of service on dependent factors performance.

In the proposed study, the effect on performance and caused by the occupational stress factors, coping and length of service for IARI and IT sector employees were categorized into three levels Low effect, Moderate Effect and High effect. Thus the outcome variable is in categorical more than 2 categories. In SPSS system these dependent variables need to be stored as nominal variables. The multinomial logistic regression is used to predict a nominal dependent variable in the study i.e. the effect on performance with occupational stress, approach and avoidance coping and length of service. The multinomial logistic regression allows interactions between independent variables to predict the dependent variable.

The multinomial logistic regression analysis measures the effect of change in variation of one of the independent variables on the variation of the dependent variable-performance and explains the variation. The effect of different inde- 
pendent variables was explained in the relative log odd ratios $(\mathrm{OR}$ or $\operatorname{Exp}(\mathscr{B}))$. The results indicated that independent variable occupational stress is the predictor of performance and IARI and IT sector employees experiencing more stress from occupational stress, when compared with Low effect on performance keeping High effect of performance as reference variable. The results are presented in the following section.

From the model fitting table indicates that final model is significantly predicting the outcome variable than intercept only model (Table 5).

The parameter of the chi-square distribution used to test the null hypothesis is defined by the degrees of freedom in the prior column. Pearson chi-square $(p-548)$ and Deviance $(p=0.520)$ assess the goodness of fit of the model and the model with four predictor variables indicates a good fit to the data (Table 6).

The Nagelkerke R-square indicates that $50.5 \%$ of the total variations in stress level occurred due to the variations among the three predictor variables (Table 7). However, these are not equivalent to $\mathrm{R}$ squares in Ordinary Linear Regression.

The -2 Log likelihood or reduced are indicated in Table 8 and the results it can be observed that all the three predictor values, occupational stress, approach coping, avoidance coping and length of service are significantly contributing meaningful to the to the model.

A Multinomial Logistic Regression was used to analyse the predictors on unordered group classification like low effect, moderate effect and high effect in terms of performance. The reference category for the outcome variable was High Effect and other two categories Low Effect and Moderate Effect were compared to this group. The first column of the Table 9 is Low effect (referring to Performance Effect) was compared to reference category High Effect. From the results

Table 5. Model fitting information to predict the performance levels.

\begin{tabular}{ccccc}
\hline \multirow{2}{*}{ Model } & Model Fitting Criteria & \multicolumn{3}{c}{ Likelihood Ratio Tests } \\
\cline { 2 - 5 } & -2 Log Likelihood & Chi-Square & df & Sig. \\
\hline Intercept Only & 996.525 & & & \\
Final & 647.695 & 348.829 & 12 & 0.000 \\
\hline
\end{tabular}

Table 6. Goodness-of-fit statistics.

\begin{tabular}{cccc}
\hline & Chi-Square & df & Sig. \\
\hline Pearson & 6230.712 & 194 & 0.548 \\
Deviance & 647.695 & 194 & 0.520 \\
\hline
\end{tabular}

Table 7. Effect of size to test the strength of the model pseudo R-Square.

\begin{tabular}{cc}
\hline Cox and Snell & 0.370 \\
\hline Nagelkerke & 0.505 \\
McFadden & 0.350
\end{tabular}


Table 8. Likelihood ratio test: performance with stress, coping levels and length of service.

\begin{tabular}{ccccc}
\hline \multirow{2}{*}{ Effect } & Model Fitting Criteria & \multicolumn{2}{c}{ Likelihood Ratio Tests } \\
\cline { 2 - 5 } & $\begin{array}{c}-2 \text { Log Likelihood of } \\
\text { Reduced Model }\end{array}$ & Chi-Square & df & Sig. \\
\hline Intercept & $647.695^{\mathrm{a}}$ & 0.000 & 0 &. \\
Occupational Stress & 889.571 & 241.875 & 2 & 0.000 \\
Approach Coping & 744.276 & 96.580 & 2 & 0.000 \\
Avoidance Coping & 668.059 & 20.364 & 2 & 0.000 \\
Length of Service & 778.347 & 130.651 & 6 & 0.000 \\
\hline
\end{tabular}

The chi-square statistic is the difference in -2 log-likelihoods between the final model and a reduced model. The reduced model is formed by omitting an effect from the final model. The null hypothesis is that all parameters of that effect are 0 . a. This reduced model is equivalent to the final model because omitting the effect does not increase the degrees of freedom.

Table 9. Parameter estimates to predict performance with occupational stress, approach coping, avoidance coping and length of service.

\begin{tabular}{|c|c|c|c|c|c|c|c|c|c|}
\hline & \multirow{2}{*}{$\begin{array}{l}\text { Performance } \\
\text { Effect }^{a}\end{array}$} & \multirow{2}{*}{ B } & \multirow{2}{*}{ Std. Error } & \multirow{2}{*}{ Wald } & \multirow{2}{*}{$\mathrm{df}$} & \multirow{2}{*}{ Sig. } & \multirow{2}{*}{$\operatorname{Exp}(B)$} & \multicolumn{2}{|c|}{ 95\% Confidence Interval for $\operatorname{Exp}(B)$} \\
\hline & & & & & & & & Lower Bound & Upper Bound \\
\hline \multirow{8}{*}{$\begin{array}{l}\text { Low } \\
\text { Effect }\end{array}$} & Intercept & 80.004 & 7.245 & 121.940 & 1 & 0.000 & & & \\
\hline & Occupational stress & -1.904 & 0.198 & 92.264 & 1 & 0.000 & 0.149 & 0.101 & 0.220 \\
\hline & Approach coping & -1.515 & 0.154 & 97.214 & 1 & 0.000 & 0.220 & 0.163 & 0.297 \\
\hline & Avoidance coping & -3.176 & 0.846 & 14.100 & 1 & 0.000 & 0.042 & 0.008 & 0.219 \\
\hline & Los 1 - 5 Years & -0.612 & 0.177 & 11.905 & 1 & 0.001 & 0.542 & 0.383 & 0.768 \\
\hline & Los 6 - 10 Years & -1.721 & 0.725 & 5.640 & 1 & 0.018 & 0.179 & 0.043 & 0.740 \\
\hline & Los 11 - 15 Years & -0.624 & 0.707 & 0.779 & 1 & 0.377 & 0.536 & 0.134 & 2.141 \\
\hline & Los $>15$ years & $0^{\mathrm{b}}$ & . & . & 0 & . & . & . & . \\
\hline \multirow{8}{*}{$\begin{array}{c}\text { Moderate } \\
\text { Effect }\end{array}$} & Intercept & 56.212 & 6.084 & 85.361 & 1 & 0.000 & & & \\
\hline & Occupational stress & -6.658 & 0.791 & 70.776 & 1 & 0.000 & 0.001 & 0.000 & 0.006 \\
\hline & Approach coping & -6.799 & 0.888 & 58.590 & 1 & 0.000 & 0.001 & 0.000 & 0.006 \\
\hline & Avoidance coping & -3.486 & 0.769 & 20.576 & 1 & 0.000 & 0.031 & 0.007 & 0.138 \\
\hline & Los 1 - 5 Years & -1.878 & 0.769 & 5.968 & 1 & 0.015 & 0.153 & 0.034 & 0.690 \\
\hline & Los 6 - 10 Years & -0.106 & 0.585 & 0.033 & 1 & 0.856 & 0.899 & 0.286 & 2.831 \\
\hline & Los 11 - 15 Years & -0.565 & 0.575 & 0.969 & 1 & 0.325 & 0.568 & 0.184 & 1.752 \\
\hline & Los $>15$ years & $0^{\mathrm{b}}$ & . & . & 0 & . & . & . & . \\
\hline
\end{tabular}

a. The reference category is: High Effect; b. This parameter is set to zero because it is redundant.

it can be observed that all the predictors occupational stress, approach coping, length of service 1 - 5 years, 6 - 10 years and $>15$ years significantly influencing the model to predict the performance. The odd ratio (OR) or the logistic coefficient $(\mathfrak{B})$ for 6 - 10 years 0.179 indicate for each predictor variable for each alternative category of the outcome variable, but not the reference category. When 
comparing low effect with High effect the odds of length of service 1 - 5 years for each year increase in service effecting the performance is 0.174 times $(95 \%$, CI $0.043-0.740, p<0.05)$, When comparing Moderate effect group with High effect group the odd ratio or logistic coefficient (B) 0.031 indicates that one unit decrease avoidance coping the odds of decreasing the performance is 0.031 times (95\%, CI 0.007 - 0.138). The length of service 11 - 15 service not a good predictor of the performance and occupational stress, approach coping and avoidance coping are good predictors of the performance. Most of the Odds ratios are (OR $<1)$ for predictors indicating a moderate level of influence in the model effecting the performance at moderate level. When comparing length of service with low effect with High effect group the length of service is a good predictor of the performance.

Therefore, we reject the null hypothesis and accept the alternate hypothesis:

$\mathrm{H}_{11}$ : Occupational stress and coping are related to the IARI and IT sector employees. However the length of service is the predictor for performance and partially accept.

$\mathrm{H}_{12}$ : Length of service is related to IARI and IT sector employees.

\section{Discussion}

The primary data gathered to structured questionnaire with 113 questions which were sub-divided into 16 factors based on their characteristic grouped as stress causing factors, coping factors, length of service and performance. These findings include the two boundaries of the Likert scale given in the analysis i.e. strongly disagree and strongly agree. The results supported the outcome of a similar study conducted by Prasad et al. (2016, 2018), Yahaya et al. (2010), Annamalai \& Nandagopal (2014). Survey research will have some deficits related to its use as these are self-reported instruments and sometimes may not be complete and reliable. The assumed shortcomings may be, once the researcher submits questionnaire to the respondent, the researcher has no idea whether respondent himself/herself provided the responses are not. The another shortcoming is, even though utmost care was taken and brief introduction as provided about the study, there is a chance the respondent may misunderstand the question/statement. This researcher has mitigated this problem with inserting reverse keyed questions, where appropriate. Further, a strong internal consistency of the instrument was confirmed by both Cronbach's alpha and Spearman-Brown split-half reliable static at overall and at independent level using ordinal data.

\section{Conclusion}

The employees of IARI and IT sector employees experienced moderate occupational stress which affects the performance. The length of service has some negative effects on performance with low effect groups. The mankind and in particular working class is exposed to various kind stressors resulting in effect on performance. The men use avoidance coping strategies for short-term benefits and 
women use approach coping strategies for long-term benefits. Some of the suggestions will improve employee performance in IARI and IT sector employees, which is job redesign, Flexible hour employment, interpersonal relations, social support and crèche services. Management should concentrate to have sessions on physical exercises and medication to improve the well-being of employees.

\section{Conflicts of Interest}

The authors declare no conflicts of interest regarding the publication of this paper.

\section{References}

Annamali, S., \& Nandagopal, R. (2014). Occupational Stress: A Study of Employee Stress in Indian ITES Industry (p. 165). New Delhi: Allied Publishers.

Awadh, I. M., Gichinga, L., \& Ahmed, A. H. (2015). Effects of Workplace Stress on Employee Performance in the County Governments in Kenya: A Case Study of Kilifi County Government. International Journal of Scientific and Research Publications, 5, $1-8$

Beehr, T. A., \& Newman, J. E. (1978). Job Stress, Employee Health and Organizational Effectiveness: A Facet Analysis, Model and Literature Review. Personnel Psychology, 31, 665-699. https://doi.org/10.1111/j.1744-6570.1978.tb02118.x

Campbell, C. H., Ford, P., Rumsey, M. G., \& Pulakos, E. D. (1990). Development of Multiple Job Performance Measures in a Representative Sample of Jobs. Personnel Psychology, 43, 277-300. https://doi.org/10.1111/j.1744-6570.1990.tb01559.x

Chand, P., \& Sethi, P. S. (1997). Organizational Factors in the Development of Work Stress. Indian Journal of Industrial Relations, 32, 457-460.

Cochran, W. G. (1977). Sampling Techniques (3rd ed.). New York: Wiley.

Cooper, C. L. (1978). Sources of Managerial and White Collar Stress. Stress at Work, 56-81.

Cronbach, L. (1951). Coefficient Alpha and Internal Structure of Tests. Psychometrika, 16, 297-334. https://doi.org/10.1007/BF02310555

Francis, A. (2008). Business Mathematics and Statistics (6th ed.). Bedford Row, London: South Western Cengage Learning EMEA, High Holborn House.

Gay, L. R., Mills, G. E., \& Airasian, P. W. (2009). Educational Research: Competencies for Analysis and Research. Student Value Edition. Upper Saddle River, NJ: Merrill..

IBM Corp (2017). IBM SPSS Statistics for Windows, Version 25.0. Armonk, NY: IBM Corp.

Irawanto, D. W., Noermiyati, \& Primasari, D. (2015). The Effect of Occupational Stress on Work Performance of Female Employees: Study in Indonesia. Asia-Pacific Journal of Management Research and Innovation, 11, 336-345.

Kaiser, H. F., \& Michael, W. B. (1975). Domain Validity and Generalizability. Educational and Psychological Measurement, 35, 31-35.

https://doi.org/10.1177/001316447503500103

Lazarus, R. S. (1966). Psychological Stress and Coping Process. New York: McGraw Hill.

Levi, L. (1998). Preface: Stress in Organizations Theoretical and Empirical Approaches. Cooper (Ed.), Theories of Organizational Stress. New York: Oxford University Press.

Lotfizadeh, M., Maimaiti, N., \& Ismail, N. H. (2014). Occupational Stress among White 
Collar Employees in Esfahan Steel Company, Iran. Malaysian Journal of Public Health Medicine 14, 79-81.

Matteson, M. T., \& Ivancevich, J. M. (1987). Controlling Work Stress: Effective Human Resource and Management Strategies. San Francisco: Jossey Bass.

Novick, M. R., \& Lewis, C. (1967). Coefficient Alpha and the Re3liability of Composite Measurements. Psychometrika, 32, 1-13. https://doi.org/10.1007/BF02289400

Pestonjee, D. M. (1999). Stress and Coping: The Indian Experience (2nd ed., pp. 216-229). New Delhi: Sage Publications.

Prasad, K. D. V., Vaidya, R., \& Anil Kumar, V. (2015). A Study on Causes of Stress among the Employees and Its Effect on the Employee Performance at the Workplace in an International Agricultural Research Institute, Hyderabad, Telangana, India. International Journal of Management Research and Business Strategy, 4, 68-82.

Prasad, K. D. V., Vaidya, R., \& Anil Kumar, V. (2016). Teacher's Performance as a Function of Occupational Stress and Coping with Reference to CBSE Affiliated School Teachers in and around Hyderabad: A Multinomial Regression Approach. Psychology, 7, 1700-1718. https://doi.org/10.4236/psych.2016.713160

Prasad, K. D. V., Vaidya, R., \& Anil Kumar, V. (2018). Association among Occupational Stress Factors and Performance at Workplace among Agricultural Research Sector Employees at Hyderabad, India. Pacific Business Review International, 10, 27-36.

Rose, J. L., \& Vega, J. F. (1984). Assessing the Sustained Effects of a Stress Management on Anxiety and Locus of Control. Academy of Management Journal, 27, 190-198.

Sateesh Kumar, K., \& Madhu, G. (2012). Analysis and Multinomial Logistic Regression Modelling Work Stress in Manufacturing Industries in Kerala, India. International Journal of Advances in Engineering \& Technology, 2, 410-418.

Schuler, R. S. (1980). Definition and Conceptualization of Stress in Organizations. Organizational Behavior and Human Performance, 25, 184-215. https://doi.org/10.1016/0030-5073(80)90063-X

Selye, H. (1956). The General Adaptation Syndrome and the Diseases of Adaptation. Journal of Clinical Endocrinology, 2, 117-230.

Selye, H. (1974). Stress without Distress. New York, 26-39.

Selye, H. (1980). Stress, Aging and Retirement. Journal of Mind and Behaviour, 1, 93-110.

Srivastava, A. K. (2001). Coping Strategy Scale. Varanasi: Rupa Psychological Centre.

Srivastava, A. K., \& Singh, A. P. (1984). The Occupational Stress Index. Varanasi: Manavaigyanic Parikshan Sansthan.

Stephen, E. B. (2014). Occupational Stress and Coping Strategies among Female Employee of Commercial Banks in Nigeria. International Journal of Scientific Research and Management, 2, 1417-1430.

Sumaneet (2005). Job Stress in Business Organisations: Causes, Consequences, and Coping Strategies. Indian Journal of Training and Development, 35, 84-92.

Suryawanshi, A., Savasani, M., \& Shah, J. A. (2015). A Study of Stress Level of Married Men and Women Using Multinomial Logistic Regression. International Journal of Scientific Research Publications, 5, 1-8.

Tread Gold, R. (1999). Transcendent Occasions: Their Relationship to Stress, Depression and Clarify of Self Concept. Journal of Humanistic Psychology, 39, 81-105. https://doi.org/10.1177/0022167899391010

William Trochim, K. M. (2006). Types of Reliability. Research Methods Knowledge Base, Web Center for Social Research Methods. 
http://www.socialresearchmethods.net/kb/reltypes.php

Yahaya, N., Yahaya, A., Tamyes, F. A., Ismail, J., \& Jaalam, S. (2010). The Effect of Various Modes of Occupational Stress, Job Satisfaction, Intention to Leave and Absentism Companies Commission of Malaysia. Australian Journal of Basic and Applied Sciences, 4, 1676-1684. 